\title{
Increase in malaria cases imported from Pakistan to Germany in 2012
}

K Stark (StarkK@rki.de) ${ }^{1}$, I Schöneberg ${ }^{1}$

1. Department for Infectious Disease Epidemiology, Robert Koch Institute (RKI), Berlin, Germany

Citation style for this article:

Stark K, Schöneberg I. Increase in malaria cases imported from Pakistan to Germany in 2012. Euro Surveill. 2012;17(47):pii=20320. Available online: http://www. eurosurveillance.org/ViewArticle.aspx?Articleld=20320

A significant increase of malaria cases imported to Germany from Pakistan was observed in 2012. As of 14 November, Pakistan was the country of infection in 32 out of 434 malaria cases in 2012, compared to zero to eight annual malaria cases (out of over 500 cases) in previous years. Physicians and public health authorities should consider malaria in febrile patients returning or migrating from Pakistan.

In the second half of 2012, there was a significant increase in malaria cases imported from Pakistan among cases of malaria reported in Germany.

Malaria is a major travel-associated disease, and is mandatorily notifiable in Germany [1]. In national surveillance, in addition to the laboratory diagnosis (Plasmodium species) information is routinely available for the majority of cases on the country of infection and on several demographic variables such as age, sex, country of origin, the individual's status in Germany (e.g. migrant, employee), chemoprophylaxis. Since 2005, between 526 and 633 imported cases of malaria were annually reported to the Robert Koch Institute (RKI, German National Public Health Institute) (2011: 562 cases) [2,3]. In the vast majority of these cases, Plasmodium infection had been acquired in African countries (2011: 89\%).

As of 14 November 2012, 32 cases of malaria imported from Pakistan were reported to RKI (out of a total number of 434 cases). Case notifications peaked in late summer with 10 cases reported in July, six in August and eight in September. This contrasts with previous years (2001-2011) where between zero and eight cases (median five cases) had been imported from Pakistan annually. Interestingly, over the same period, the number of malaria cases imported from India has remained stable. As of 14 November 2012, 13 malaria cases were reported from India and from 2001 to 2011 between six and 17 cases (median 10 cases).

Of the 32 cases reported in 2012 so far, 30 were persons originating from Pakistan (23 migrants/asylum seekers/refugees, three employees, two students, two persons with unknown status). The majority of them have been living in Germany since the end of 2011 or the beginning of 2012. For five persons originating from Pakistan it was reported that they had travelled to Pakistan and stayed there between four and eight weeks. Cases were predominantly male (24 males, seven females, one case without information on sex), and 21 were aged between 20 and 39 years (range 9 to 73 years). In the majority of cases $(n=23)$ Plasmodium vivax was detected. Of the remaining nine cases, three were classified as Malaria tertiana (i.e. classical microscopic characteristics for $P$. vivax/P. ovale but no further differentiation between these two Plasmodium species reported), two were notified as $P$. falciparum infections, two as mixed infections, and two cases were reported with Plasmodium detection but no further specification of the species was provided. None of the malaria patients had taken chemoprophylaxis.

\section{Discussion and conclusion}

The increase in malaria cases from Pakistan seen in Germany in 2012 may reflect changing patterns of malaria risk in the country, or a growing number of migrants to the country from Pakistan. In Pakistan, there is a countrywide malaria risk in areas below $2,000 \mathrm{~m}$ altitude, and about $70 \%$ of the malaria incidence is due to $P$. vivax [4]. According to the World Health Organization, malaria has re-emerged in recent years as a major cause of morbidity in Pakistan. The disease mainly affects the districts with suboptimal healthcare service delivery along the international borders with Afghanistan and Iran. Mass population movements, low immune status of the population, climatic changes, poor socioeconomic conditions, declining health infrastructure, and mounting drug and insecticide resistance in parasites and vectors, all contribute to the huge disease burden [5].

It would be interesting to know if other countries in Europe have been observing a similar increase in malaria cases from Pakistan in 2012. Pakistan is not a common destination for tourists or professionals from European countries. However, persons of Pakistani origin may travel back and forth (e.g. to visit relatives and friends), and soldiers from non-endemic countries on mission in Afghanistan may also be exposed to malaria 
while travelling through Pakistan. Therefore, our findings are relevant to travel medicine. Persons travelling to Pakistan should be counselled on the potential risk of acquiring malaria and on adequate prevention measures.

In Greece, in the context of the autochthonous malaria outbreaks in summer 2011 in the Evrotas region, $P$. vivax infection had been diagnosed in a number of migrant workers mainly from Pakistan. Their malaria importation status remained unclear but it is possible that they had acquired the infection already in the country of origin $[6,7]$. In the 2012 autochthonous outbreak in Greece also a high proportion of cases concerned migrants from malaria-endemic countries [8].

Physicians and public health experts in non-endemic countries should be aware of the possibility of malaria in patients with fever returning or originating from countries such as Pakistan where malaria has reemerged in recent years but which are often not considered as classical malaria endemic countries. In such patients timely testing for malaria is necessary because it facilitates timely and adequate treatment. This is of high benefit to the individuals affected by malaria and it could also reduce the risk of local outbreaks in areas where vector abundance and climatic conditions may make transmission possible.

\section{References}

1. Bales S, Baumann HG, Schnitzler N. Infektionsschutzgesetz. [Protection against Infection Act]. Stuttgart, 2003, W. Kohlhammer. German.

2. Robert Koch Institute (RKI). Reiseassoziierte Infektionskrankheiten 2011. [Travel-associated infectious diseases 2011]. Epidemiologisches Bulletin. 2012;43:429 37. German. Available from: http://www.rki.de/DE/ Content/Infekt/EpidBull/Archiv/2012/Ausgaben/43 12. pdf; jsessionid $=9$ A6EEE4A80B549F4A66D 5DEB8D 27 2F59.2_cid226?__blob=publicationFile

3. Schöneberg I, Stark K, Altmann D, Krause G. Importierte Malaria in Deutschland - Infektionsländer und Erregerspezies von 1993-2007. [Imported malaria in Germany--countries of infection and parasite species, 1993-2007]. Gesundheitswesen. 2008;70(4):256-61. German.

4. World Health Organization (WHO). World Malaria Report 2011. Geneva: WHO. 2011. Available from: http://www.who.int/ malaria/world_malaria_report_2011/9789241564403_eng.pdf

5. World Health Organization (WHO). Regional Office for the Eastern Mediterranean.Cairo: WHO. Pakistan: Malaria control and elimination. [Accessed 21 Nov 2012]. Available from: http://www.emro.who.int/pak/programmes/roll-back-malaria. html

6. Danis K, Baka A, Lenglet A, Van Bortel W, Terzaki I, Tseroni $M$, et al. Autochthonous Plasmodium vivax malaria in Greece, 2011. Euro Surveill. 2011;16(42):pii=19993. Available from: http://www.eurosurveillance.org/ViewArticle. aspx?Articleld=19993

7. European Centre for Disease Prevention and Control (ECDC). Rapid Risk Assessment. Update on autochthonous Plasmodium vivax malaria in Greece. Stockholm: ECDC. 11 Oct 2011. Available from: http://www.ecdc.europa.eu/en/publications/ Publications/131003_TER_Malaria_Greece_Risk_Assessment. pdf

8. European Centre for Disease Prevention and Control (ECDC). Epidemiological update: Malaria risk to travellers in Greece remains low. Stockholm: ECDC. 7 Sep 2012. Available from: http://www.ecdc.europa.eu/en/press/news/Lists/News/ ECDC DispForm.aspx?List $=32$ e 43 ee 8 -e230-4424-a78385742124029 a\&ID $=721$ \& RootFolder $=\% 2$ Fen $\% 2$ Fpress $\% 2$ Fnews $\% 2$ FLists\%2FNews 